Slavica

bruxellensia

\section{Slavica bruxellensia}

Revue polyphonique de littérature, culture et histoire

slaves

$2 \mid 2009$

Femme(s)

\title{
Edito \#2
}

\section{Dorota Walczak}

\section{OpenEdition \\ Journals}

\section{Édition électronique}

URL : http://journals.openedition.org/slavica/149

DOI : $10.4000 /$ slavica. 149

ISSN : 2034-6395

\section{Éditeur}

Université libre de Bruxelles - ULB

\section{Édition imprimée}

Pagination : 5

ISSN : 2031-7654

\section{Référence électronique}

Dorota Walczak, «Edito \#2 », Slavica bruxellensia [En ligne], 2 | 2009, mis en ligne le 15 février 2009, consulté le 22 septembre 2020. URL : http://journals.openedition.org/slavica/149 ; DOI : https:// doi.org/10.4000/slavica.149

Ce document a été généré automatiquement le 22 septembre 2020.

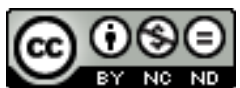

Les contenus de Slavica bruxellensia sont mis à disposition selon les termes de la Licence Creative Commons Attribution - Pas d'Utilisation Commerciale - Pas de Modification 3.0 France. 


\section{Edito \#2}

\section{Dorota Walczak}

1 Wisława Szymborska, lauréate du prix Nobel de Littérature en 1996, commence son poème "Portrait féminin "par ces vers : Il faut qu'elle soit au choix / Qu'elle change de sorte que surtout rien ne change. Ainsi, elle met en exergue le questionnement sur la condition et le conditionnement contemporains de la femme. Le statut de la femme dans la société et sa place dans la littérature ont fortement changé, surtout depuis les années 1960. Et pourtant, les archétypes et stéréotypes continuent à inspirer et à révolter les écrivains, les critiques et les lecteurs de tous genres.

2 Loin des cadrages féministe, érotique et lyrique (certes intéressants mais également réducteurs), sans s'inscrire dans la ligne droite du gender, post-, neo- et autres « studies », ce deuxième numéro de «SLAVICA BRUXELLENSIA » propose des textes qui gravitent autour de la «femme » dans un spectre très large : femme à la fois auteur et thème, sujet et objet de réflexion, lecteur et traducteur de son propre cheminement intellectuel...

3 Ainsi, l'article de Wojciech Tomasik revient sur les débuts poétiques de Szymborska en discutant l'interprétation d'un de ses poèmes réalistes socialistes, Éric Metz expose la panoplie poétique déployée par Konstantin Bal'mont, le chantre des femmes " étrangères », et Katia Vandenborre se penche sur l'image de la princesse dans le conte polonais et sur une curieuse influence du symbole religieux au sein de la littérature polonaise. Dans l'interview menée par Sarah Flock et Richard Vacula, la Tchèque Petra Hůlová témoigne de son activité de romancière et partage ses pensées sur la façon actuelle d'écrire et de parler d'une femme. La partie de notre revue consacrée à la traduction présente des fragments du roman épistolaire La Pousse de mûrier sauvage, inédit en français, de Lena Eltang, auteur russe très en vogue et magnifiquement traduite par Anne Delizée.

4 L'auteur mis à l'honneur dans ce numéro est l'écrivain et traducteur polonais Stanisław Barańczak. Aussi, comme dans le premier numéro, six critiques viennent compléter cette édition et offrent un échantillon éclectique des nouvelles parutions littéraires et scientifiques de l'univers culturel slave.

5 Merci encore à toute l'équipe de la rédaction et à vous, chers lecteurs, vous qui nous avez manifesté tant de sympathie, d'encouragements et de félicitations à la sortie du 
premier numéro. Le prochain rendez-vous est fixé au 15 juin 2009 ! Bonne lecture à tous!

\section{AUTEUR}

\section{DOROTA WALCZAK}

Responsable de la Chaire de Polonais, section de Langues et Littératures modernes, option Slaves, de l'Université Libre de Bruxelles (Belgique) ; Rédactrice en chef de «Slavica Bruxellensia » 